\title{
Conjoint job-share: conjugal bliss
}

\author{
Andrew West and Karey Taylor
}

By describing a conjoint job-shore in a single registra post on an cocute adult poychlatilic ward in Wellington, Now Zealand, this paper contributes to the growing iftercture on the subject of part-fime training. We shared, on the one hand a registrar post and, on the other hand, our domestic life and the ralising of our first chlld. We supplement our subjective impressions with information gathered from the multidisciplinary team, using a short queetionnaire.

Job-sharing is the sharing of responsibilities within a single post. Sharing of a post, but with separate responsibilities, is job-splitting (Meager \& Buchan, 1989). This distinction may be hairsplitting, but it points to one of the difficulties that would-be job-sharers meet in the medical profession. There appears to be a reluctance on everybody's part to allow any responsibilities to be truly shared. Perhaps this is one reason why. despite the apparent popularity of job-sharing as a means of working part-time (Routh, 1991), most part-time trainees are working separate "supernumerary" positions.

The current literature on job-sharing in the medical profession consists mainly of subjective descriptions of individual experiences. Van den Brink \& Sanders (1995) have described their experience as a parent couple, firstly working a job-share in which they took it in turns to occupy full-time posts for six-month periods and, secondly, simultaneously working in separate parttime posts.

Like Van den Brink \& Sanders, we have experienced a number of different ways of combining two careers with joint child-raising. One of these was to share a single six-month registrar post on an acute in-patient ward in Wellington, New Zealand. Unlike the situations which preceded it, which were job-splits and were arranged relatively easily, this was a true jobshare, and its inception met with significant resistance.

\section{The job}

We joined one of two acute adult in-patient teams on a 28 bed ward servicing Wellington city. We saw a full range of adult mental illness, although we did not have ongoing responsibility for compulsorily admitted patients who were transferred to another hospital. The multidisciplinary team was led by the professor of the untversity department of psychological medicine. We were the registrar.

We shared the patients between us, maintaining an ongoing responsibility for our "own" patients, but having also some knowledge of our partner's patients. At midday every day we exchanged our one-year-old child, and any pertnent accompanying information, for ward matters. We scheduled appointments with our own patients and their families at times that we knew we would be at work, and not too close to handover time. It was only on rare occasions that we needed to see each other's patients, or make decisions concerning their management.

\section{Anticipatory anxiety}

The medical team-members and the senior nurse/managers were sceptical and worried as to how sharing of the post might affect patient care and the running of the team. In general the non-medical staff had an open-minded approach; some clearly intrigued by the novelty, others curious as to how it would work. A single condition was placed upon our acceptance into the post: this was that we should each make an appearance on the ward every day. We were both to attend the twice-weekly team meeting. but were able to do this one at a time, the order of patients discussed being arranged accordingly.

From our point of view, we were eager to join the team and we thought that we would cope at least adequately. Even so, our confidence was shaken by the scepticism and concern expressed by others and we started the post feeling that we had to perform more than adequately to vindicate our claim to the post.

\section{Subjective experience}

For us the situation was almost ideal. We found the midday handover could be done in only a few minutes, the domestic and professional handovers taking roughly equal time. We needed brief periods of childcare for the rare occasions when we were both required at the team meeting simultaneously. Our timetables were posted in the ward office, and other team members quickly learned how to predict our movements. One of our fears had been that we would spend our 
evenings exchanging work-related information, but this proved not to be the case.

Our impression, reinforced by the replies to our questionnaires, was that we became full members of the team and the shared registrar post became, temporarily, part of the team's identity. We were able to enjoy a prestiglous placement that would have been denied us had the necessary flexibility not been there.

\section{The team view}

In order to find out more about the problems, predicted and experienced by the team as a consequence of our sharing the post, we circulated all team-members, including the clerical and support staff, with a questionnaire which asked for retrospective information on people's reactions to the imminent arrival of a job-share into the post, and their current views on the impact it was having on the ward. Two-thirds of the way through the placement 27 questionnaires were circulated. Eighteen were returned. Seven respondents identified aspects of the ward's working that had been affected in a negative way. Sixteen identified aspects that had been affected positively.

The negative effects were around the fact that the doctor present might not be the "right one". This was experienced as a minor inconvenience by some staff members, and was thought to be a source of confusion to the occasional patient. One team member considered it a problem that management decisions arising first thing in the morning might be made by the non-primary doctor.

The positive comments could be divided into two groups: the effusive and personal supportive comments that are of little relevance to this article but were of major supportive relevance to us at the time; and more dispassionate comments around the theme of greater responsive flexibility with a choice of gender, greater range of opinion and expertise available, and that two halves amount to more than one whole. One person saw the greater flexibility that was required of the team as a welcome challenge.

When asked what conditions should be placed upon any possible future job-share, almost every respondent identified two needs: clear allocation of patients and times of avallability of each doctor, and excellent communication between the sharers.

\section{Comment}

It has been shown possible for two people to share a single registrar post on an acute psychiatric ward provided the team and patients are clearly and repeatedly informed how the responsibilities for individual patients, and the working week, are being shared, and provided the communication between sharers is efficient and complete. It would appear that the inconveniences caused by the sharing of the post, and the extra effort that was required of all team members, was balanced by an increase in flexibility and an increase in the richness of the experience for most participants.

The keys to a successful job-share partnership have been said to include "mutual trust, loyalty, flexibility, and a commitment to each other ...." (Baildam et al, 1991). This could equally be said of the parenting relationship. Skills acquired in one context can be transferred to another. The main benefit that the conjoint nature of this jobshare conferred was that we were well-used to working as a team and our channels of communication were already well-established.

Parental couples at similar stages of training and who both want to remain closely involved in their children's development might be encouraged to apply for a conjoint job-share. Employing institutions may be reassured that this arrangement can work. In an atmosphere in which greater attention is being paid to part-time training and job-sharing, more attention could be paid to the conjoint job-share.

\section{Acknowledgements}

We wish to thank Professor Graeme Mellsop, and the staff at the Psychiatric Unit, Wellington Public Hospital for supporting us in this job-share.

\section{References}

BAILDAM, E. M., EWING, C. I., JONES, R., et al (1991) Job sharing. Archives of Diseases of Childhood, 66, 282-283.

MEAGER, N. \& BUCHAN, J. (1989) Job sharing in the National Health Service. Institute of Manpower Studies, Report no. 174.

RouTH, C. P. (1991) Part-time training in psychiatry: what trainees want. Psychiatric Bulletin, 16, 614-615.

VAN DEN BRINK, E. \& SANDERS, A. (1995) Two types of parttime registrar training in psychiatry. Psychiatric Bulletin. 19. 163-165.

*Andrew West, Senior Registrar in Child \& Adolescent Psychiatry, Berkshire Adolescent Unit, Wokingham Hospital, Barkham Rd, Wokingham, Berks RG41 2RE; and Karey Taylor, Clinical Assistant in Liaison Psychiatry. John Radcliffe Hospital, Headington, Oxford

*Correspondence 